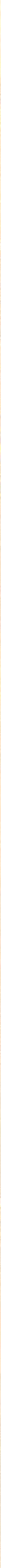




\section{Dinâmicas e interações em ambientes pessoais de aprendizagem no ensino superior}

Dynamics and interactions in environments personal learning in higher education

DOI: $10.15213 /$ REDES.N12.P344

MARIBEL SANTOS MIRANDA PINTO

\section{RESUMO}

Existe um vasto leque de informação à qual os alunos têm acesso, nomeadamente através dos dispositivos móveis com ligação à Internet, os quais possuem ou usam com grande facilidade e diariamente. Assumir que fazemos parte da sociedade do conhecimento é algo arriscado, porque existe ainda muito a fazer de forma a aproveitar as tecnologias na educação. Atendendo aos diversos cenários onde decorrem as aprendizagens dos nossos alunos do ensino superior, sentimos necessidade de promover novas práticas aliadas aos interesses tecnologicos desta geração, com o intuito de promover a leitura de artigos de caráter científico relacionadas em diversas Unidades Curriculares. A presente investigação de carácter qualititativo recorre à metodologia de investigação-ação e está a ser desenvolvida no Instituto Politécnico de Viseu, na Escola Superior de Educação, no ano letivo 2014/2015. Os participantes deste estudo são os alunos das Licenciaturas de Educação Social e de Educação Básica na Unidade Curricular de Tecnologias de Informação e Comunicação.

PALAVRAS-CHAVE: AMBIENTES PESSOAIS DE APRENDIZAGEM; WEB 2.0; TECNOLOGIAS NA EDUCAÇÃO; ENSINO SUPERIOR. 


\section{ABSTRACT}

A wide range of information to which students have access, for example through mobile internet connection, which own or use with great ease and daily. Assume that we are part of the knowledge society is risky, because there is still much to do to take advantage of the technologies in education. Given the various scenarios where derive the learning of our students, we need to promote new practices allied to technological interests of this generation in order to promote reading related scientific character of articles. This qualititativo-driven research refers to research-action methodology and is being developed at the Polytechnic Institute of Viseu, in the School of Education in the school year 2014/2015. The participants are the students of Undergraduate Social Education and Basic Education in the Course of Information and Communication Technologies.

KEYWORDS: PERSONAL LEARNING ENVIRONMENTS; WEB 2.0; TECHNOLOGIES IN EDUCATION; HIGHER EDUCATION.

\section{INTRODUÇÃo}

As tecnologias fazem parte do nosso quotidiano e da vida pessoal das novas gerações, contudo ainda são vísiveis inúmeras barreiras quando estes pretendem entrar num contexto formal de aprendizagem. Hernández (2011) refere que o ambiente organizacional das nossas instituições educativas, bem como todo o processo de ensinoaprendizagem torna-se muito previsível, sendo demasiado estático e desinteressante para as características dos atuais educandos. Entendemos que a aprendizagem não se pode circunscrever a um único contexto, em que o professor assume o papel de único detentor do conhecimento apoiado pelos manuais escolares.

O desenvolvimento tecnológico que se vive em pleno século XXI, na área das tecnologias de informação e comunicação (TIC) perspetiva uma educação suportada por meios digitais, incluindo a Internet, dispositivos móveis, redes sociais e aplicações da chamada Web 2.0, meios que assumem um papel de relevo e se constituem como verdadeiros nós de redes de aprendizagem online, em qualquer lugar e a qualquer hora.

Para o desenvolvimento de aprendizagens em rede é necessário acreditar que,

346 | ISSN 1696-2079 
"digital learning styles include fluency in new media, online communities, guided mentoring, video games, or collective reflection via blogs, podcasts, wiki's, Flickr, Twitter, and other forms of social media. Effective online learning design should provide engaging content which allows the pupil to draw connections between the context of the learning objectives while utilizing various forms of social media" (BAIRD, 2006:s/p).

Attwell (2007) revela que os PLE proporcionam um novo enfoque da utilização das tecnologias para a aprendizagem (cit in Cabero-Almenara, Osuna, \& Cejudo, 2010). Adell y Catañeda (2010) acrescentam que os PLE são "el conjunto de herramientas, fuentes de Información, conexiones y actividades que cada persona utiliza de forma asidua para aprender" (cit in Cabero-Almenara et al., 2010).

\section{ENQUADRAMENTO TEÓRICO}

\section{A) AMBIENTES PESSOAIS DE APRENDIZAGEM}

Os novos cenários educativos impregnados de inúmero recursos tecnológicos possibilitam novas metodologias de trabalho com os alunos. Numa perspetiva de ensino superior em que cada vez mais se valoriza o trabalho autonómo é necessário proporcionar novos desafios que motivem e envolvam os alunos na construção individual da aprendizagem.

Reconhecemos que os ambientes pessoais de aprendizagem permitem a cada utilizador ter um papel ativo na construção da sua própria aprendizagem que envolve, por sua vez, outros utilizadores o que se traduz numa rede de conhecimento alargada.

Estes princípios convergem na procura de uma prática colaborativa na concepção, construção e disponibilização em rede, de novos conhecimentos e potencialidades para uma utilização colectiva. Para Downes (2005)

"in a nutshell, what was happening was that the Web was shifting from being a medium, in which information was transmitted and consumed, into being a platform, in which content was created, shared, remixed, repurposed, and passed along. And what people were doing with the Web was not merely reading books, listening to the radio or watching TV, 
but having a conversation, with a vocabulary consisting not just of words but of images, video, multimedia and whatever they could get their hands on. And this became, and looked like, and behaved like, a network" (DOwNEs, 2005, s/p).

Esta "Era Digital" oferece recursos que potenciam contextos diversificados de aprendizagem suportados por tecnologias móveis e acessíveis em qualquer lugar e a qualquer hora. Os incomparáveis desafios e conteúdos que advêm da Internet fomentam necessidades de conhecimentos num espaço curto de tempo, a fim de absorver e utilizar para benefício próprio informação acessivel através da variedade de recursos que a Web 2.0 nos oferece. Como descreve Dias (2008).

"A dimensão social da participação transformou a rede num espaço mais democrático e generalizado de publicação e partilha, promovendo a diminuição da distância social e da integração online através da acessibilidade tecnológica, e o consequente aumento da fluência digital" (DIAS, 2008, p.5).

De acordo com Santos, Pedro, \& Almeida (2011) "os PLE não se apresentam como uma ferramenta pré-determinada e imposta ao indivíduo pela instituição de ensino formal mas antes como um espaço dinâmico, que é construído autonomamente pelo aprendente" (sANTos et al., 2011, p.77).

Neste sentido e atendendo ao contexto actual da nossa sociedade impregnada de tecnologias e que desenvolve a maior parte das suas interacções online urge que docentes e instituições de ensino se envolvam nesta mudança.

De acordo com Shaikh \& Khoja, (2011) "torna-se necessário que o professor promova experiências personalizadas de aprendizagem que cultivem as competências de aprendizagem autónoma e reflexiva de cada estudante. Assim, o professor assume-se não como a figura central no processo de ensino-aprendizagem, mas como alguém que, numa relação de igualdade, participa e promove a discussão e a reflexão, ajudando os estudantes a gerirem o seu ambiente de aprendizagem" (cit in sANTos et al., 2011, p.78).

Por outro lado, "a utilização de PLE no Ensino Superior pode, deste modo, ser uma forma adequada de promover o desenvolvimento dessas competências essenciais nos dias de hoje" (sANTos et al., 2011, p.78). 


\section{B) WEB 2.0}

A variedade de inúmeros dispositivos móveis aos quais temos acesso diariamente possibilitam aos contextos educativos novas formas de interatividade e de aprendizagem.

De acordo com Downes (2005) a natureza da Internet começa a deixar as suas marcas na forma como as pessoas a passam a utilizar. Estas mudanças começam a diluir a totalidade das indústrias como um todo (a quem pertence a indústria informática) e estas mudanças não são exclusivas da educação, na verdade, a educação tem ficado aquém de algumas destas tendências e está apenas começa a sentir o rasto das potencialidades da Web 2.o. Este autor refere que são as gerações mais novas as que mais aderem às novas tendências e utilizam com frequência as ferramentas da Web 2.0 ou também, reconhecida como Web social.

Ocorre, assim, uma mudança a nível de contextos de aprendizagem, que não são reconhecidos como tal, mas que conduzem a cenários de aprendizagem nunca antes imaginados. Consiste num processo baseado na exploração e construção pessoal do conhecimento mediado pelas Tecnologias de Informação e Comunicação, em que instituições e professores podem, também, desempenhar um papel crucial.

Passa a ser cada vez mais imprescindivel recorrer a estratégias e actividades adequadas, para uma utilização efectiva das tecnologias e a sua transversalidade nas diversas áreas de conhecimento. Torna-se relevante a valorização dos momentos ditos "informais" nos quais ocorrem aprendizagens muito significativas, em que a orientação e medição do professor podem enriquecer estas experiências.

As TIC e a Internet actualmente reconhecida por Web 2.0 constituem-se no Ciberespaço como novas formas de projectar a formação e a educação. É a capacidade de usufruir de diversos recursos que temos à nossa disposição e encontrar formas de construir colaborativamente novos conhecimentos.

Perante as reflexões que temos vindo a desenvolver sobre a Sociedade da Informação e do Conhecimento, da qual as TIC e a Internet fazem parte, parece-nos que estamos preparados para discutir uma outra temática, que tem vindo a ser reconhecida desde 2005 com o nome Web 2.0 e instituída por Tim O'Reilly (2005b), paradigma que antevia uma segunda geração da Internet.

O que difere a concepção Web 2.0 de outras tecnologias que surgem e se disseminam no mundo tecnológico é que este conceito descreve com maior precisão um tipo de tecnologia e integra os produtos que dela advém. O'Reilly (2005b), anuncia a passagem de uma Internet ou como ele próprio designa 
Web 1.0 para a Web 2.0, onde deixamos de ser meros observadores para nos tornarmos construtores dos ambientes em que decorre a interacção.

O'Reilly (2005a) define a Web 2.0 pode ser definida como:

"the network as platform, spanning all connected devices; Web 2.0 applications are those that make the most of the intrinsic advantages of that platform: delivering software as a continually-updated service that gets better the more people use it, consuming and remixing data from multiple sources, including individual users, while providing their own data and services in a form that allows remixing by others, creating network effects through an "architecture of participation," and going beyond the page metaphor of Web 1.0 to deliver rich user experiences" (o'REILLY, 2005a).

O'Reilly (2005b), demarca sete princípios que constituem a Web 2.0 e estes são: A World Wide Web como Plataforma; Aproveitamento da Inteligência Colectiva; A Gestão de Bases de Dados como Competência Básica; O Fim do Ciclo de Actualizações de Versões de Software; Modelos de Programação Simples; Software não Limitado a um Único Dispositivo e Experiências Enriquecedoras dos Utilizadores.

Por outro lado, Romaní \& Kuklinski (2007) acrescentam que esta nova rede digital mais conhecida por Web 2.0 deixa de ser um expositor de conteúdos multimédia para passar a ser uma plataforma aberta, construída com base na participação dos indivíduos. São evidentes os diversos termos utilizados em redor deste conceito, tais como, software social, redes sociais, arquitectura de participação, entre outros conceitos que emergem relacionados com este fenómeno.

Anderson (2007) sugere dois tipos de respostas para definir Web 2.0, uma curta e outra longa. A resposta curta é, para muitas pessoas, a referência a um grupo de tecnologias, tais como: wikis, podcasts, blogs, o RSS, etc., as quais facilitam a promoção de redes sociais, onde qualquer indivíduo é capaz de acrescentar e editar um determinado espaço de informação. A resposta mais longa é bastante mais complexa pois envolve dimensões que requerem conhecimentos mais aprofundados de economia, tecnologia e novas concepções sobre a sociedade em rede.

A maior visibilidade, à qual assistimos com o advento da Web 2.0, têm sido as variadas redes sociais que aqui proliferam "integrando indivíduos de todo o mundo, segundo interesses de determinada temática, agrupados 
por instituições educativas e por grupos de amigos que, por sua vez, integram outros amigos, tornando esta teia cada vez maior e sem fim visível" (MIRANDA et al., 2008, p.96).

De entre estas redes sociais destacam-se as que são desenvolvidas em ferramentas tais como, Orkut, Hi5, MySpace, Facebook, Ning, My Opera, MyBlogLog (Yahoo) e o mais debatido na actualidade, o Second Life "que exibe uma virtualidade maior, permitindo integrar contextos físicos específicos, desenhados no mundo virtual, com a possibilidade de recorrer a personagens (avatars) que podem ser adquiridas, configuradas e assumidas neste contexto de interacção" (MIRANDA et al., 2008:96), também considerado como um ambiente de realidade e interacção virtual.

Nesta esfera de reflexões em torno do que poderá definir melhor a Web 2.o encontrámos quem circunscreva este conceito ao fenómeno social que se vive actualmente com as tecnologias e com a Internet. Para Hernández (2007)

"Probablemente el trasfondo en los cambios de Web 2.0 sea más social que tecnológico, pues si bien es cierto que los cambios son posibles gracias a los avances tecnológicos, estos cambios son el reflejo de una necesidad social que se ha ido conformando a la par de la tecnología, teniendo como una de las primeras muestras la tendencia de los programas de código abierto, que proponía una apertura no sólo en cuanto acceso, sino también en cuanto a colaboración en el desarrollo de programas" (HERNANDEZ, 2007:3).

Se por um lado as redes sociais agradam aos mais jovens e adultos que participam neste mundo social virtual, por outro lado, outras ferramentas da Web 2.0 começam a ser cada vez mais utilizadas no âmbito profissional e em diversos sectores da sociedade real, da qual destacamos a educação. As ferramentas que mais proliferam no âmbito educativo são os blogs, que quer a nível pessoal quer profissional acompanham o desenvolvimento de actividades ao longo dos anos lectivos. É possível encontrar blogs de diversas temáticas (áreas disciplinares) e dirigidos a públicos-alvo (níveis educativos) diversificados, todos eles com conteúdos de relevância, em que alguns se prolongam no tempo e outros acabam no esquecimento após o término da situação para a qual foi desenvolvido.

Como profissionais de educação importa questionar como este movimento global em torno da Web 2.0 afecta os contextos educativos reais? Que tipo de utilização fazem os docentes e alunos destas ferramentas? Com que 
objectivos as utilizam? Que resultados obtêm desta utilização? Que benefícios ou inconvenientes encontram nestas ferramentas?

A interactividade preconizada por Berners-Lee (1996) aquando da difusão da Internet em grande escala previa o que talvez hoje já seja possivel através das ferramentas Web 2.0 ao nível da construção de conhecimento. Esta interatividade em rede passou a incluir outro elemento, a criatividade em que o resultado da junção de duas palavras, traduz o que de real hoje é possível construir em rede, a "intercreatividade" (cit in ROMANí \& KUKLINSKI, 2007).

\section{METODOLOGIA DE INVESTIGAÇÃo}

A presente investigação de carácter qualititativo recorre à metodologia de investigação-ação e está a ser desenvolvida no Instituto Politécnico de Viseu, na Escola Superior de Educação, no ano letivo 2014/2015. Os participantes deste estudo são os alunos da Licenciatura de Educação Social e da Licenciatura de Educação Básica. Como técnicas de recolha de dados recorremos a um Questionário Online cujas dimensões são baseadas num Modelo de Análise de Interações para Comunidades Online (Miranda-Pinto, 2009), de forma a analisar o papel de cada aluno, numa perspectiva individual e de autreflexão sobre a participação num Ambiente Pessoal de Aprendizagem.

Recorremos à metodologia de investigação-acção por entender que existe uma falha a colmatar no ensino superior, que incentive os alunos a uma leitura orientada, de artigos de caráter cientifico da especialidade de cada Unidade Curricular. De acordo com Amado \& Cardoso (2014), o nosso problema foi "diagnosticado em contexto social (caráter social); a intervenção ou acção para resolver a situação anterior; de novo a reflexão para produzir conhecimento acerca dessa transformação (caráter autoavaliativo)" (AMADO \& CARDOSO, 2014, p.188).

Nesta investigação propomo-nos estudar as potencialidades dos ambientes híbridos e pessoais de aprendizagem em contextos de Ensino Superior, para a promoção da leitura, reflexão, trabalho colaborativo e gestão de conteúdos numa plataforma online. Para este efeito recorremos a uma plataforma de acesso livre, SAPO Campus (Figura 1) desenvolvida na Universidade de Aveiro - Portugal (http://campus.sapo.pt), mas que prevê um registo e configuração para a criação de comunidades de aprendizagem online e grupos. De acordo com Santos, Pedro, \& Almeida (2012), "O SAPO Campus - plataforma integrada de serviços da Web 2.0 suportada institucionalmente - surgiu em 2009 fruto de uma parceria de investigação e desenvolvimento entre a 
Universidade de Aveiro (UA) e a empresa Web portuguesa" (Santos et al., 2012, p.2470).

A plataforma SAPO Campus "foi desenvolvida inicialmente para o contexto do ensino superior (http://campus.ua.sapo.pt) estando o seu conceito base relacionado com a implementação da plataforma a dois níveis distintos. Assim, a par de um conjunto independente de serviços e ferramentas disponibilizados pela instituição (blogues, wiki, fotos e vídeos), existe um nível de agregação e de integração de widgets com vista ao desenvolvimento da cultura dos PLE entre os membros da comunidade da UA." (Santos et al., 2012, p.2470).

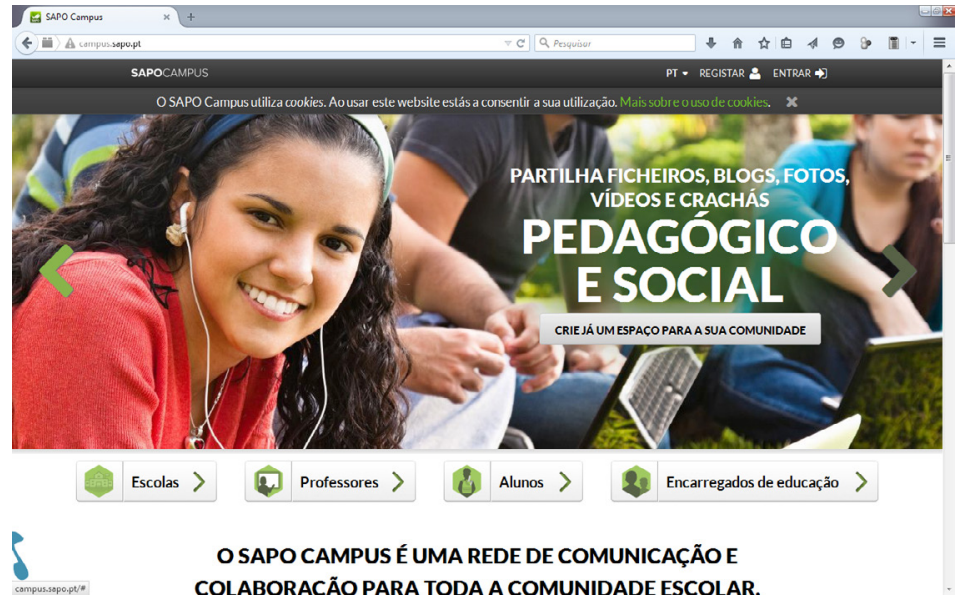

Figura 1 - Plataforma SAPo CAMpus

Atendendo à natureza desta plataforma e numa perspectiva de usufruir das suas potencialidades para alunos do Ensino Superior optámos por recorrer a este serviço para a nossa investigação. Criamos um espaço na plataforma denominada por "TICESEV" aberto a todos os alunos da ESEV, que pretendam partilhar práticas e experiências com tecnologias na educação, que pelas suas características denominamos de Comunidade de Aprendizagem (ver Figura 2). 


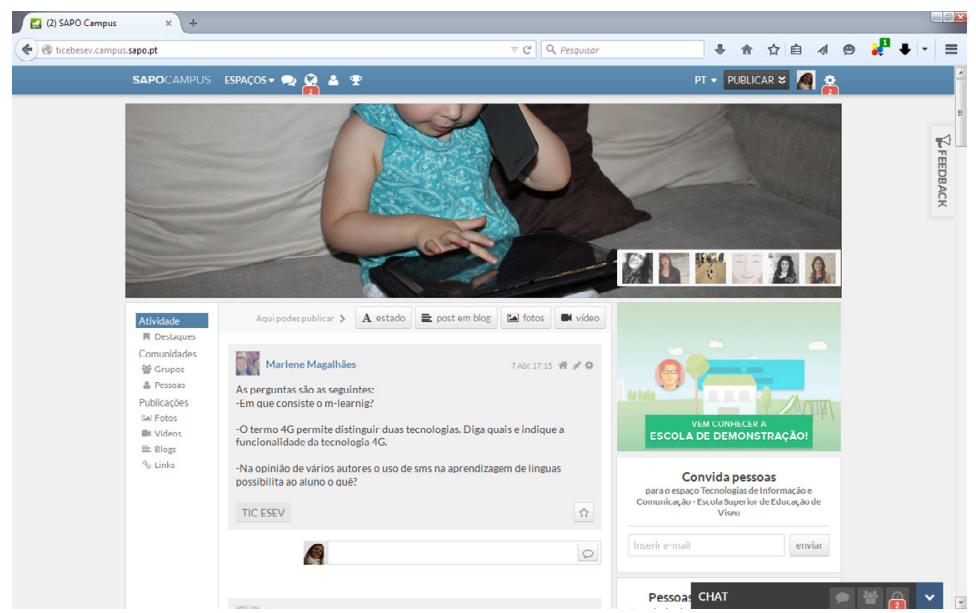

Figura 2 - Comunidade TICESEV

No entanto, dentro desta comunidade decidimos criar um grupo que denominamos por "Tecnologias", direccionado aos alunos que num determinado semestre pudessem usufruir desta plataforma experimentando dois pápeis, o de alunos e o de docentes, com acesso à gestão de recursos na plataforma e de forma individual. É também neste espaço onde decorre o maior fluxo de comunicação devido às dinâmicas e interacções que são implementadas numa perspetiva de construção pessoal das aprendizagens.

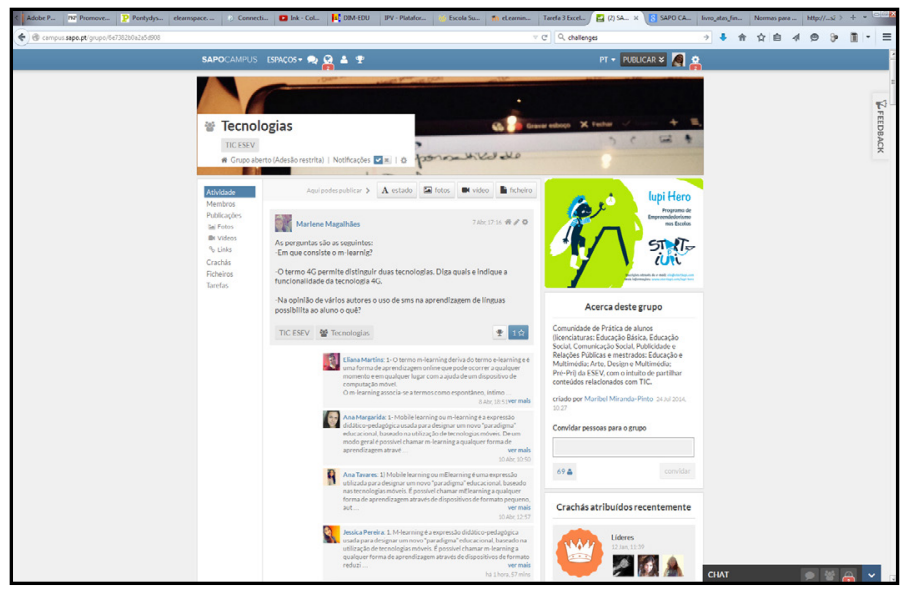

FiguRA 3 - GRUPo TECNOLOGIAS 
Para a dinamização deste espaço e gestão do mesmo por parte do deocente e alunos foram criados "Crachás" que funcionam como fator de motivação para a leitura de artigos científicos na área das tecnologias na educação (ver Figura 4).

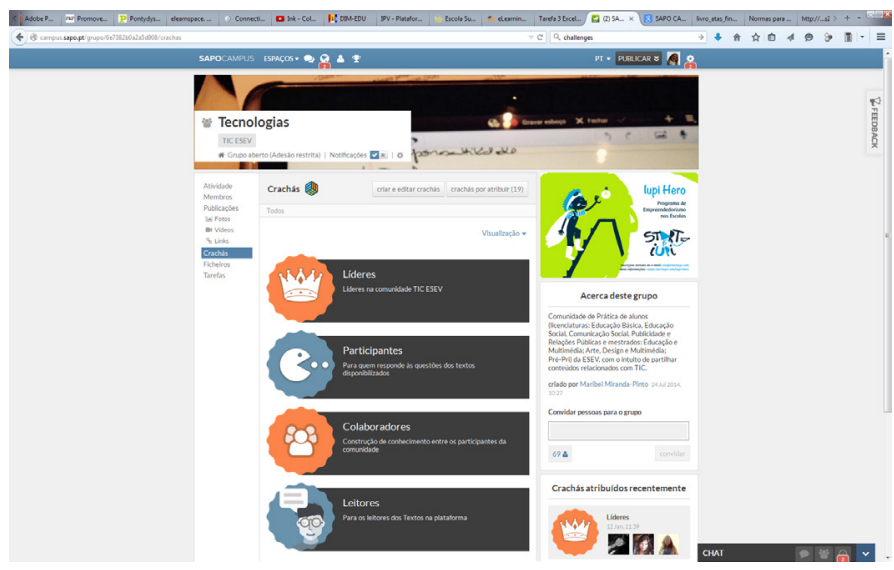

Figura 4 - CRAchás

A atribuição de Crachás é realizada pelos próprios alunos aos seus colegas e confirmada a respetivaatribuição pelo docente (ver Figura 5). Para este efeito e em debate com os alunos do Curso de Educação Social foi decidido criar quatro crachás:

- Líderes - Líderes na comunidade TIC ESEV

- Participantes - Para quem responde às questões dos textos disponibilizados

- Colaboradores - Construção de conhecimento entre os participantes da comunidade

- Leitores - Para os leitores dos Textos na plataforma 


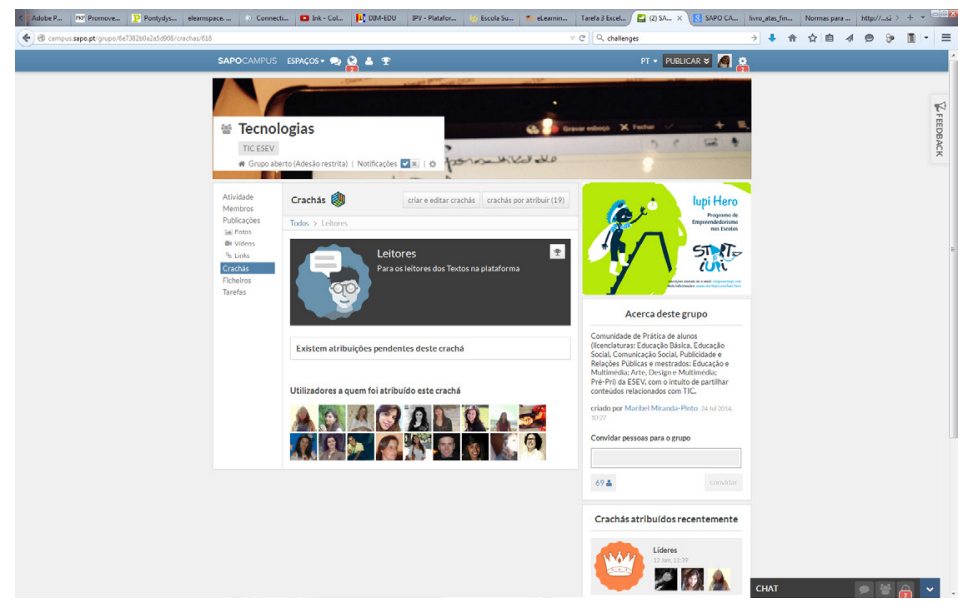

Figura 5 - ARtibuição de Crachá

Neste Grupo “Tecnologias" participaram no $1^{\circ}$ semestre, deste ano letivo, 46 alunos da Licenciatura de Educação social, na Unidade Curricular de Oficina das Tecnologias de Informação e Comunicação. No $2^{\circ}$ semestre participam no desenvolvimento das atividades e no mesmo formato os alunos da Licenciatura de Educação Básica na Unidade Curricular de Tecnologias de Informação e Comunicação. Todos os alunos destas e outras licienciaturas têm sempre acesso à Comunidade "TICESEV" e ao Grupo "Tecnologias", o que difere é que apenas dinamizam atividades no papel de gestor, os alunos que se encontram na Unidade Curricular em funcionamento.

As atividades no ambiente pessoal de aprendizagem tem a duração de 15 semanas, nas quais os alunos participam individualmente e em grupo quando assumem o papel de gestores das atividades. $O$ plano de atividades tem como base a leitura de artigos científicos na área das tecnologias na educação, mobile learning, ambientes pessoais de aprendizagem, comunidades de prática, entre outros. As atividades principais decorrem da seguinte forma:

$\mathrm{Na} 1^{\text {a }}$ sessão (aula presencial) é disponibilizado aos alunos uma pasta com os diversos artigos de cárater cientifico na área das Tecnologias de Informação e Comunicação. São formados grupos de trabalho para a dinzamização online numa determinada semana, a restante intervenção do aluno é individual e espera-se que seja ele próprio a fazer a gestão do seu tempo e a sua participação individual.

$\mathrm{Na} 2^{a}$ sessão (aula presencial) é formalizada a constituição de grupos de trabalho e cada grupo apresenta a escolha do artigo que vai analisar e 
dinamizar com diversas atividades, no decorrer de uma semana.

Desde a $3^{\mathrm{a}}$ sessão à $14^{\mathrm{a}}$ sessão (online) iniciam as atividades no que consideramos como Ambiente Pessoal de Aprendizagem, mas que denominamos como Comunidade.

- Todas as semanas um grupo é responsável pela gestão da plataforma e por dinamizar o artigo de caráter científico que escolheu. A dinamização encara uma vertente social e outra pedagógica e pode recorrer a elementos externos (vídeos, entrevistas, apresentações, etc) ao artigo científico, para ajudar a clarificar ou enriquecer a temática que está a ser debatida.

- Os restantes alunos participam individualmente nas atividades de leitura, reflexão, questionamento e interação diversificada, promovida pelo grupo dinamizador.

- No final de cada semana cada grupo dinamizador é responsável por atribuir "Crachás" a todos os participantes de forma individual. Podem ser atribuídos todos os "Crachás", desde que o participante em questão preencha os requisitos. Esta análise à participação é feita em grupo, mas cada elemento do grupo pode optar por não atribuir "Crachá" se não o considerar pertinente. Em suma, apesar deste processo avaliativo ser em grupo, cada aluno tem autonomia para avaliar. A atribuição do "Crachá" de Líder é referenciado pelos alunos individualmente, mas apenas é atribuído pelo docente da Unidade Curricular. Este "Crachá” é atribuído individualmente e não ao grupo, com o intituito de premiar a boa gestão $\mathrm{da}$ atividade, as iniciativas que foram bem sucedidas e o bom funcionamento entre os diversos participantes.

$\mathrm{Na} 15^{\mathrm{a}}$ sessão (aula presencial) cada aluno preenche um questionário online, onde avalia a sua participação no decorrer destas 15 semanas, numa perspetiva de auto-reflexão sobre a sua interacção individual, num ambiente de aprendizagem online.

Relativamente ao questionário de avaliação da participação nesta comunidade foram consideradas as dimensões previstas no Modelo de Análise para Comunidades Online (MIRANDA-PINTO, 2009), que nesta investigação assume um caráter quantitativo por representar a participação individual de cada aluno na comunidade, numa perspetiva de auto-avaliação. Para este efeito recorremos a uma escala de Likert, com proposições para cada uma das dimensões e afirmações que integram cada uma destas dimensões em análise (PARDAL \& CORREIA, 1995). Recorremos ao Google Docs para a construção do questionário (ver Figura 6) e para auto-avaliação da participação. 


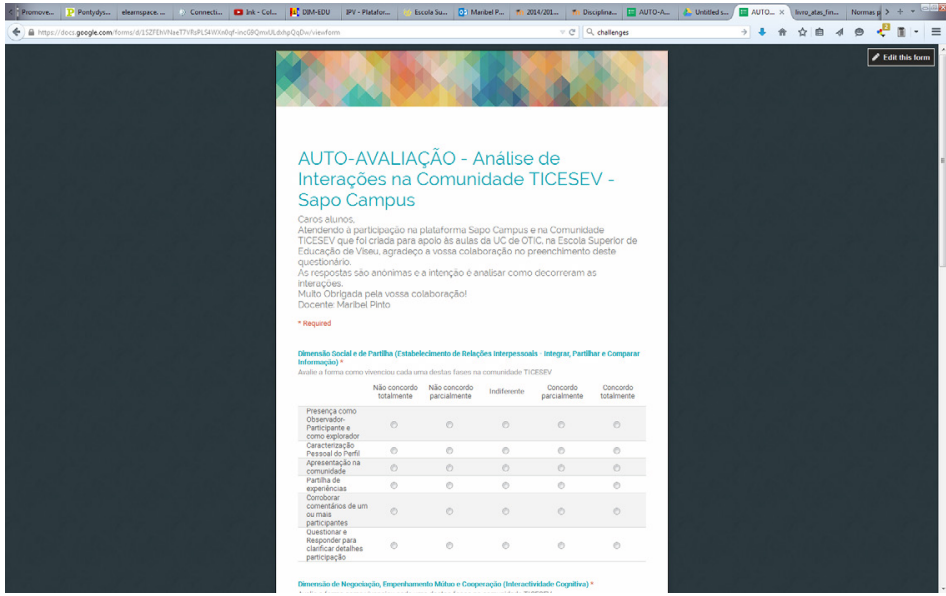

Figura 6 - QUESTIONÁRIO ONLINE

As dimensões em análise nesta investigação e que advém do Modelo de Análise de interacções para Comunidades Online (Miranda-Pinto, 2009, p.187) integra as seguintes dimensões, que por sua vez integra indicadores para análise:

1. Dimensão Social e de Partilha (Estabelecimento de Relações Interpessoais - Integrar, Partilhar e Comparar Informação)

a. Presença como Observador-Participante e como explorador

b. Caracterização Pessoal do Perfil

c. Apresentação na comunidade

d. Partilha de experiências

e. Corroborar comentários de um ou mais participantes

f. Questionar e Responder para clarificar detalhes de alguma participação

2. Dimensão de Negociação, Empenhamento Mútuo e Cooperação (Interactividade Cognitiva)

a. Identificação de Áreas de Interesse entre os participantes

b. Negociação ou esclarecimento dos significados dos diversos termos utilizados

c. Proposta e negociação sobre novas áreas de debate

d. Cooperação na realização de actividades entre os participantes

e. Empenhamento mútuo de práticas diversificadas 


\section{Dimensão de Colaboração e Construção de Conhecimento (Interactividade Metacognitiva)}

a. Partilha de informação, argumentação e integração de novos contributos

b. Debate sobre a informação partilhada e estabelecimento de um consenso

c. Reflexão crítica dos participantes e construção partilhada do conhecimento

4. Dimensão de Liderança e Moderação em Ambientes Online (Factores de Sustentabilidade)
a. Identificação de Líderes e Moderadores
b. Estratégias de Liderança e Moderação
c. Evidência discursiva de orientação explícita

5. Dimensão de Construção de Identidade em Ambientes Online (Diferenciação entre CoP)

a. Percepção da presença cognitiva

b. Percepção da presença social

O preenchimento do questionário de auto-avaliação da participação na Comunidade "TICESEV" foi realizada na última aula presecial (Janeiro 2015), onde também tivémos oportunidade de auscultar os alunos sobre esta experiência.

\section{APRESENTAÇÃo de RESULTAdos}

Numa perspetiva de apresentação de resultados do questionário recorremos às dimensões em análise, para uma percepção mais objetiva e com o intuito de tecer alguma descrição necessária para uma melhor compreensão.

\section{Dimensão Social e de Partilha (Estabelecimento de Relações Interpessoais - Integrar, Partilhar e Comparar Informação)}

No indicador referente à Presença como Observador-Participante e como explorador, num total de 46 alunos, $60,9 \%$ avalia que a sua presença individual no que diz respeito ao estabelcimento de relações interpessoais, com o intuito de integrar, partilhar e comparar informação foi concretizada parcialmente. Temos ainda que 30,4\% refere que contretizou efetivamente esta dimensão. É possível, perante os resultados da auto-avaliação realizada 
pelos alunos, evidendiar que este indicador foi concretizado positivamente, revelando a presença da maior parte dos alunos neste ambiente pessoal de aprendizagem (ver Gráfico 1).

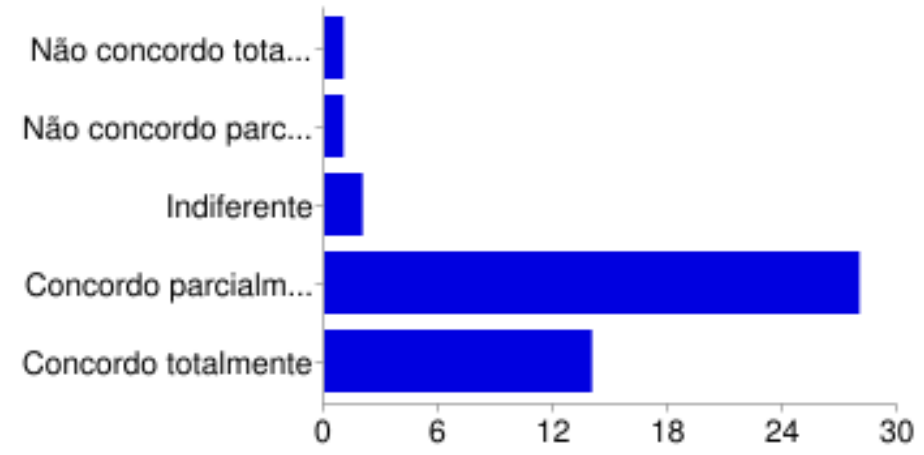

Gráfico 1 - Presença como Observador-Participante

\begin{tabular}{|l|l|l|}
\hline Não concordo totalmente & 1 & $2.2 \%$ \\
\hline Não concordo parcialmente & 1 & $2.2 \%$ \\
\hline Indiferente & 2 & $4.3 \%$ \\
\hline Concordo parcialmente & 28 & $60.9 \%$ \\
\hline Concordo totalmente & 14 & $30.4 \%$ \\
\hline
\end{tabular}

Relativamente ao indicador Caracterização Pessoal do Perfil os alunos perspetivaram, na sua maioria 54,3\% numa concordância parcial e 37\% numa concordância total que este espaço também lhes permite definir o seu perfil pessoal (ver Gráfico 2).

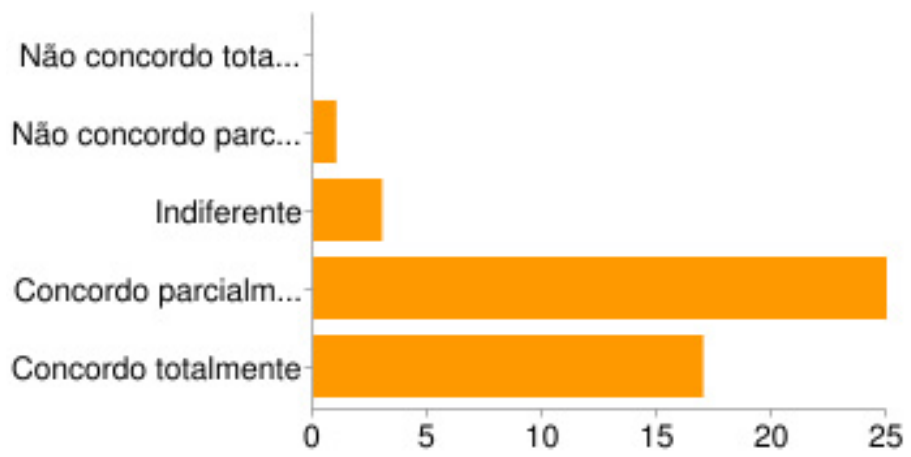


POLÍTICAS PÚBLICAS Y DESARROLLO REGIONAL EN LA SOCIEDAD DE LA INFORMACIÓN:

Gráfico 2 - Caracterização Pessoal do Perfil

\begin{tabular}{|l|l|l|}
\hline Não concordo totalmente & 0 & $0 \%$ \\
\hline Não concordo parcialmente & 1 & $2.2 \%$ \\
\hline Indiferente & 3 & $6.5 \%$ \\
\hline Concordo parcialmente & 25 & $54.3 \%$ \\
\hline Concordo totalmente & 17 & $37 \%$ \\
\hline
\end{tabular}

No indicador Apresentação na Comunidade os alunos perspetivaram que este foi concretizado totalmente $(34,8 \%)$ e parcialmente $(63 \%)$, sendo que apesar de já se conhecerem presencialmente sentiram necessidade de deixar uma mensagem de apresentação para iniciar as suas interações quando estas eram em grupo (ver Gráfico 3).

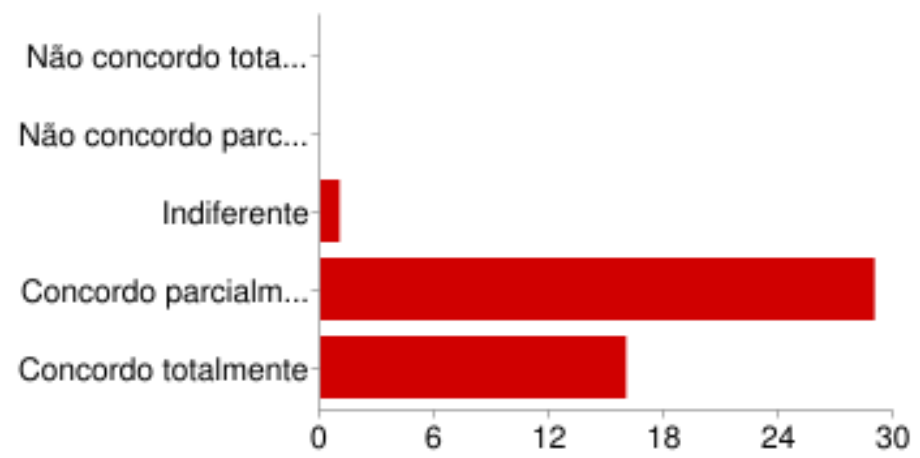

Gráfico 3 - ApresentaÇÃo NA COMUNIDAdE

\begin{tabular}{|l|l|l|}
\hline Não concordo totalmente & 0 & $0 \%$ \\
\hline Não concordo parcialmente & 0 & $0 \%$ \\
\hline Indiferente & 1 & $2.2 \%$ \\
\hline Concordo parcialmente & 29 & $63 \%$ \\
\hline Concordo totalmente & 16 & $34.8 \%$ \\
\hline
\end{tabular}

No que diz respeito à Partilha de Experiências esta também foi evidente com uma concrodância total de $45,7 \%$ e parcial de $47,8 \%$, o que revela que 
este espaço proporcionou condições para este tipo de interações e foi na sua maioria vivenciada por cada aluno (ver Gráfico 4).

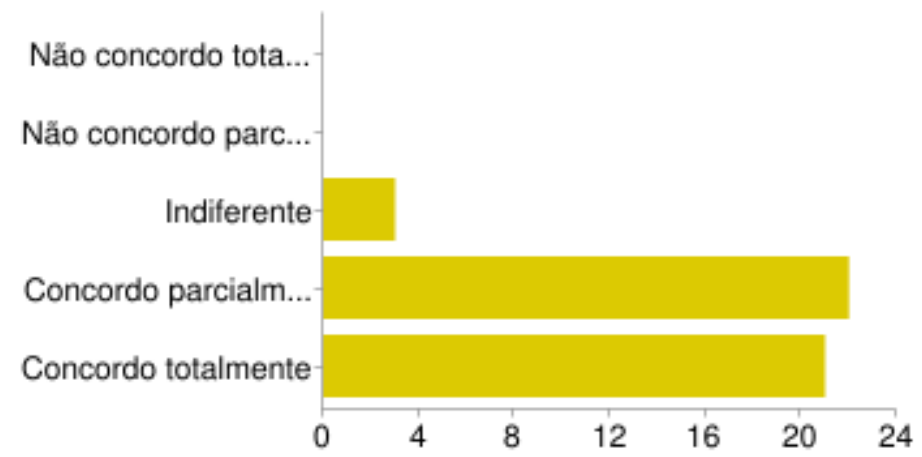

Gráfico 4 - Partilha de Experiências

\begin{tabular}{|l|l|l|}
\hline Não concordo totalmente & 0 & $0 \%$ \\
\hline Não concordo parcialmente & 0 & $0 \%$ \\
\hline Indiferente & 3 & $6.5 \%$ \\
\hline Concordo parcialmente & 22 & $47.8 \%$ \\
\hline Concordo totalmente & 21 & $45.7 \%$ \\
\hline
\end{tabular}

Relativamente a Corroborar Comentários de um ou mais Participantes a auto-avaliação reflete a tomada de consciência de uma atividade que apesar de mostrar dados positivos (Concordância Total com 26,1\% e Concordância Parcial com 58,7\%) esta inclui alunos que se posicionaram mais abaixo por entenderem que não tiveram participação neste indicador (ver Gráfico 5).

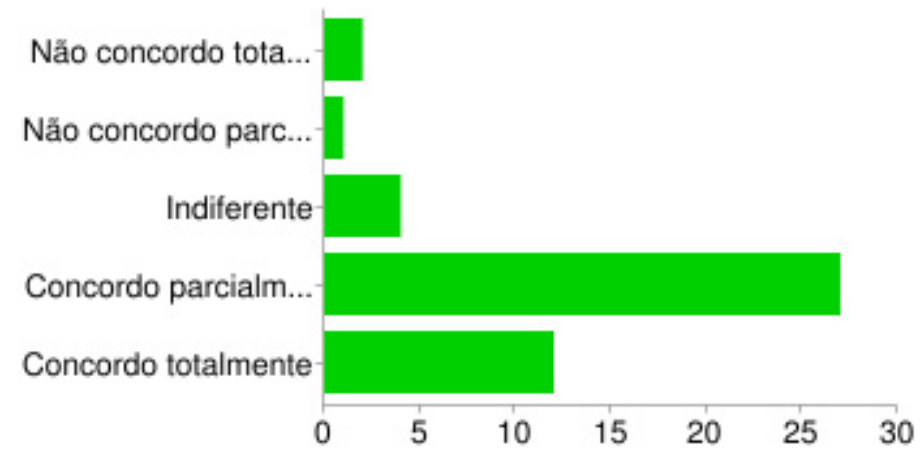


POLÍTICAS PÚBLICAS Y DESARROLLO REGIONAL EN LA SOCIEDAD DE LA INFORMACIÓN: TENDENCIAS Y RETOS

Gráfico 5 - Corroborar Comentários de um ou mais Participantes

\begin{tabular}{|l|l|l|}
\hline Não concordo totalmente & 2 & $4.3 \%$ \\
\hline Não concordo parcialmente & 1 & $2.2 \%$ \\
\hline Indiferente & 4 & $8.7 \%$ \\
\hline Concordo parcialmente & 27 & $58.7 \%$ \\
\hline Concordo totalmente & 12 & $26.1 \%$ \\
\hline
\end{tabular}

No indicador Questionar e Responder para clarificar detalhes participação é visível uma concordância total de $32,6 \%$ e concordância parcial de 58,7\% que reflete que este foi concretizado com sucesso na maioria (ver Gráfico 6).

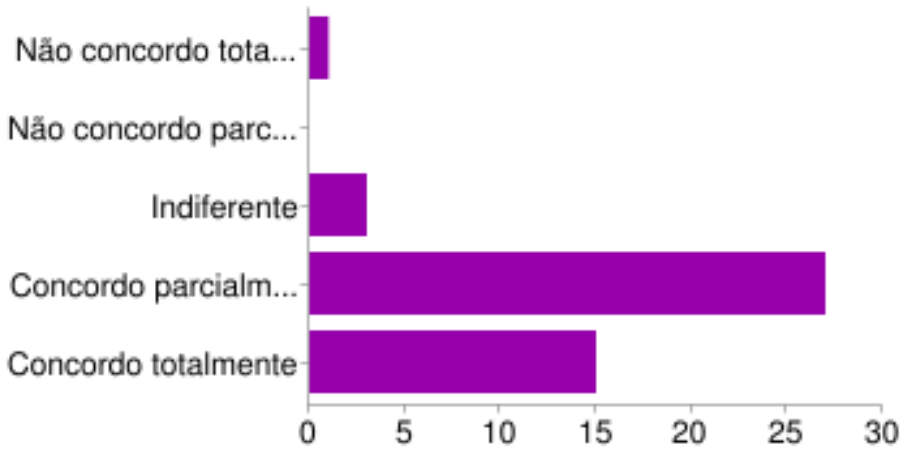

GrÁfico 6 - Questionar E RESPONDER PARA CLARIFICAR DETALHES PARTICIPAÇÃo

\begin{tabular}{|l|l|l|}
\hline Não concordo totalmente & 1 & $2.2 \%$ \\
\hline Não concordo parcialmente & 0 & $0 \%$ \\
\hline Indiferente & 3 & $6.5 \%$ \\
\hline Concordo parcialmente & 27 & $58.7 \%$ \\
\hline Concordo totalmente & 15 & $32.6 \%$ \\
\hline
\end{tabular}

\section{Dimensão de Negociação, Empenhamento Mútuo e Cooperação (Interactividade Cognitiva)}

Relativamente ao indicador Identificação de Áreas de Interesse entre os 
participantes é notório que esta foi evidenciada parcialmente num total de $63 \%$ e totalmente em $30,4 \%$, o que revela que os alunos percepcionaram os interesses dos colegas nas leituras e temáticas que foram abordadas (ver Gráfico 7).

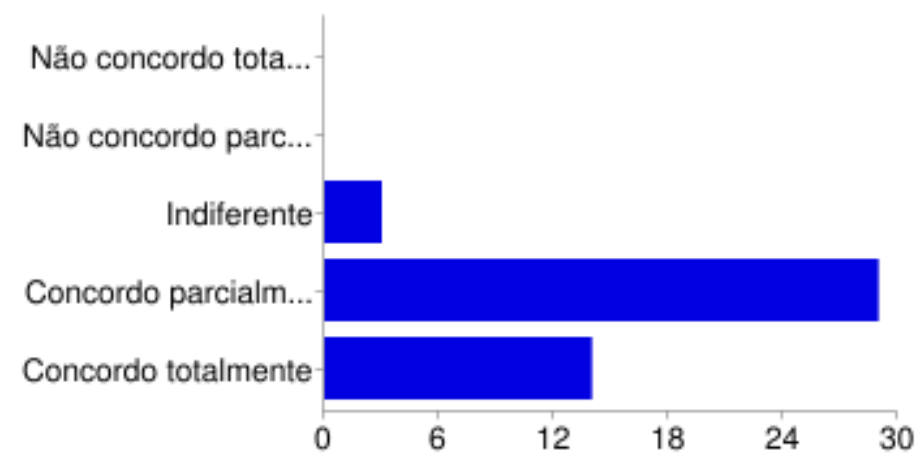

GrÁfico 7 - IdentificAÇÃo de ÁrEAS de INTERESSE ENTRE OS PARTICIPANTES

\begin{tabular}{|l|l|l|}
\hline Não concordo totalmente & 0 & $0 \%$ \\
\hline Não concordo parcialmente & 0 & $0 \%$ \\
\hline Indiferente & 3 & $6.5 \%$ \\
\hline Concordo parcialmente & 29 & $63 \%$ \\
\hline Concordo totalmente & 14 & $30.4 \%$ \\
\hline
\end{tabular}

Quando se trata do indicador Negociação ou esclarecimento dos significados os alunos entenderam na sua maioria (concordo totalmente $28,3 \%$ e concordo parcialmente $63 \%$ ) que houve espaço para colcoar questões e responder a dúvidas pessoais sobre as temáticas contidas nos artigos científicos (ver Gráfico 8 


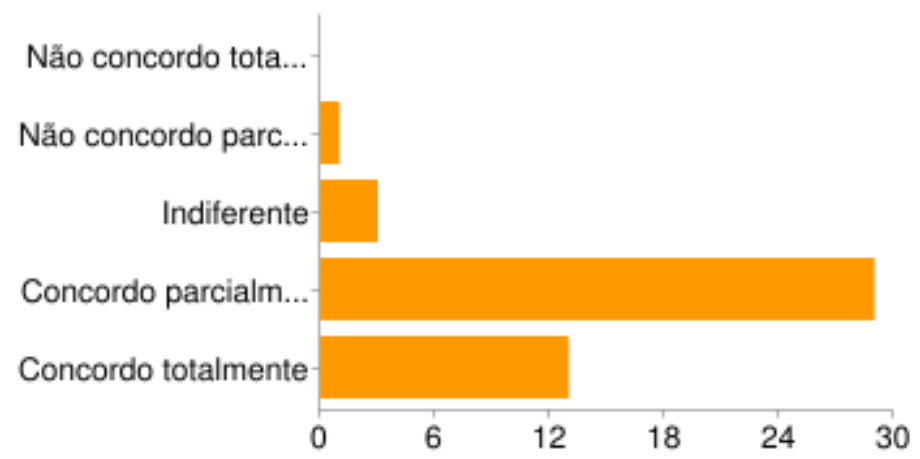

Gráfico 8 - Negociação oU ESCLARECimento dos Significados

\begin{tabular}{|l|l|l|}
\hline Não concordo totalmente & 0 & $0 \%$ \\
\hline Não concordo parcialmente & 1 & $2.2 \%$ \\
\hline Indiferente & 3 & $6.5 \%$ \\
\hline Concordo parcialmente & 29 & $63 \%$ \\
\hline Concordo totalmente & 13 & $28.3 \%$ \\
\hline
\end{tabular}

Relativamente ao indicador Proposta e negociação sobre novas áreas de debate foi visível (concordo totalmente com $28,3 \%$ e concordo parcialmente com $58,7 \%$ ) a partilha de outras referências em diversos formatos (vídeos, apresentações, etc) para complementar os textos de caráter científico e de forma a colocar mais informação para debate (ver Gráfico 9).

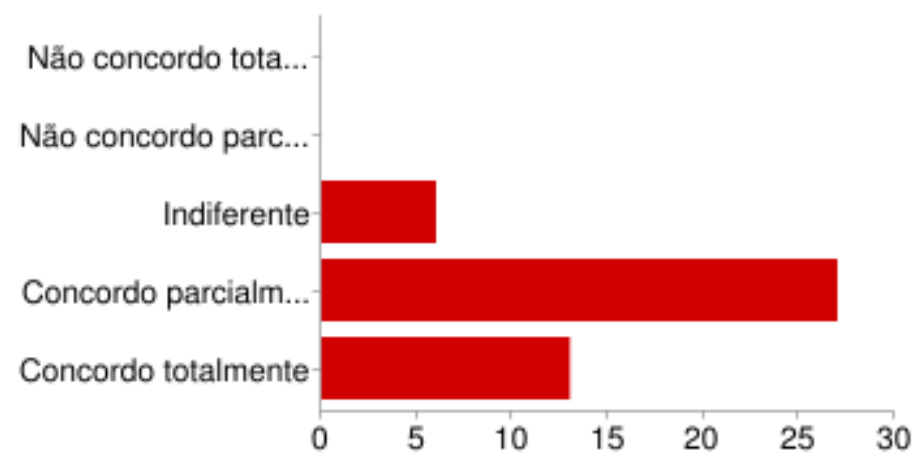

Gráfico 9 - Proposta E NegociaçÃo SObRe Novas ÁREAS de debate 


\begin{tabular}{|l|l|l|}
\hline Não concordo totalmente & 0 & $0 \%$ \\
\hline Não concordo parcialmente & 0 & $0 \%$ \\
\hline Indiferente & 6 & $13 \%$ \\
\hline Concordo parcialmente & 27 & $58.7 \%$ \\
\hline Concordo totalmente & 13 & $28.3 \%$ \\
\hline
\end{tabular}

No indicador Cooperação na realização de actividades entre os participantes foi evidente que os alunos concretizaram, na sua maioria (concordo totalmente com 32,6\% e concordo parcialmente com $63 \%$ ), com sucesso esta fase. Os alunos revelam interesse em cooperar com os outros numa perspetiva de entendimento do artigo científico (ver Gráfico 10).

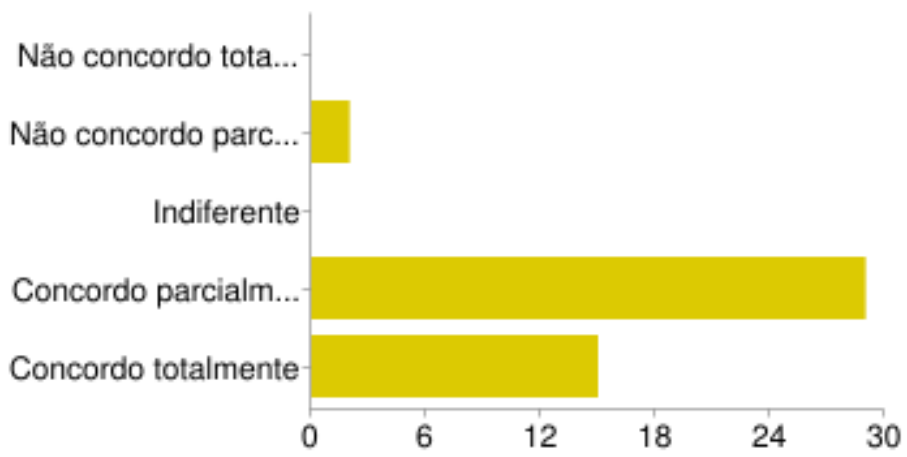

GRÁfICO 10 - COOPERAÇÃo NA REALIZAÇÃo DE ACTIVIDADES ENTRE OS PARTICIPANTES

\begin{tabular}{|l|l|l|}
\hline Não concordo totalmente & 0 & $0 \%$ \\
\hline Não concordo parcialmente & 2 & $4.3 \%$ \\
\hline Indiferente & 0 & $0 \%$ \\
\hline Concordo parcialmente & 29 & $63 \%$ \\
\hline Concordo totalmente & 15 & $32.6 \%$ \\
\hline
\end{tabular}

Relativamente ao indicador Empenhamento mútuo de práticas diversificadas os dados revelam que este empenhamentou foi vivenciado de uma forma positiva pela maior parte dos alunos (concordo totalmente com $26,1 \%$ e concordo parcialmente com $65,2 \%$ ), (ver Gráfico 11 ). 


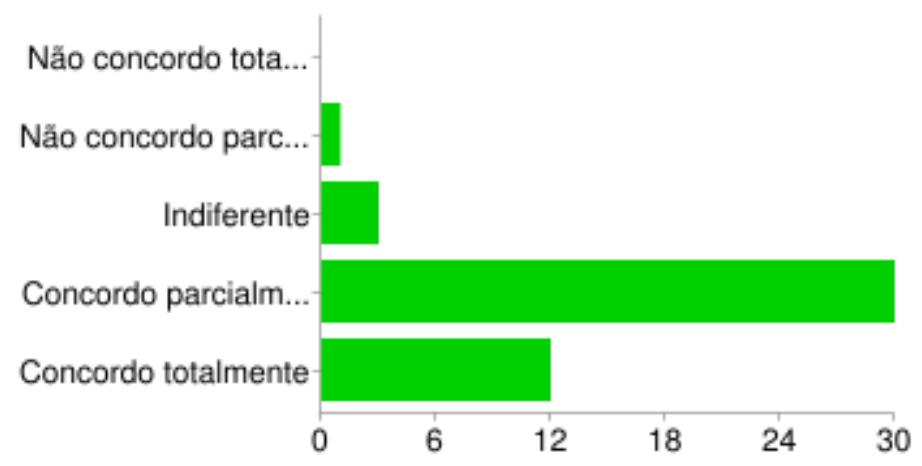

GRÁFICO 11 - EMPENHAMENTO MÚTUO DE PRÁTICAS DIVERSIFICADAS

\begin{tabular}{|l|l|l|}
\hline Não concordo totalmente & 0 & $0 \%$ \\
\hline Não concordo parcialmente & 1 & $2.2 \%$ \\
\hline Indiferente & 3 & $6.5 \%$ \\
\hline Concordo parcialmente & 30 & $65.2 \%$ \\
\hline Concordo totalmente & 12 & $26.1 \%$ \\
\hline
\end{tabular}

\section{Dimensão de Colaboração e Construção de Conhecimento (Interactividade Metacognitiva)}

No indicador Partilha de informação, argumentação e integração de contributos os alunos consideram que concretizaram esta fase de forma positiva (concordo totalmente com $37 \%$ e concordo parcialmente com $58,7 \%$ ), pois as leituras foram sempre complementadas com a integração de outros contributos que enriqueceram a constução do seu próprio conhecimento (ver Gráfico 12). 


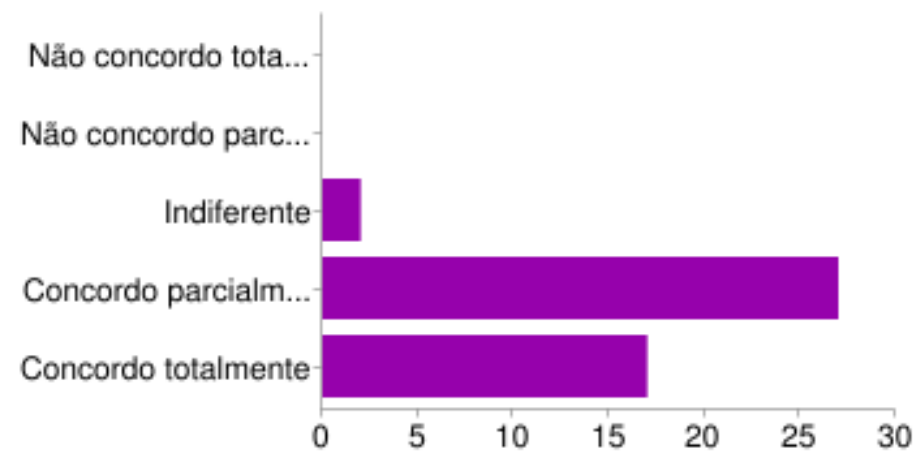

Gráfico 12 - PARTILHA DE INFORMAÇÃo, ARGUMENTAÇÃo E INTEGRAÇÃo DE CONTRIBUTOS

\begin{tabular}{|l|l|l|}
\hline Não concordo totalmente & 0 & $0 \%$ \\
\hline Não concordo parcialmente & 0 & $0 \%$ \\
\hline Indiferente & 2 & $4.3 \%$ \\
\hline Concordo parcialmente & 27 & $58.7 \%$ \\
\hline Concordo totalmente & 17 & $37 \%$ \\
\hline
\end{tabular}

Relativamente ao indicador Debate sobre a informação partilhada e estabelecimento consenso é evidente que a discussão sobre os artigos científicos existiu de forma positiva revelando uma concordância total de 39,1\% e uma concordância parcial de 52,2\% (ver Gráfico 13).

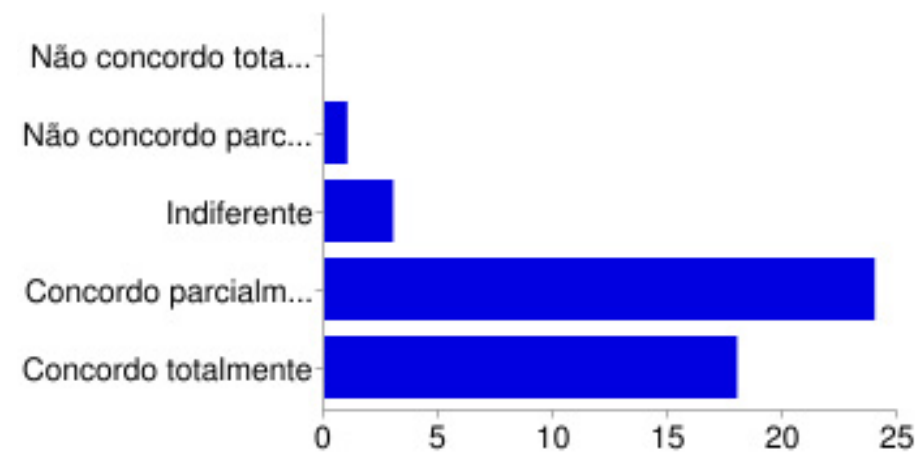

Gráfico 13 - Debate SObRe A INFORMAÇÃo PARTILHADA E ESTABELECIMENTO CONSENSO 


\begin{tabular}{|l|l|l|l|}
\hline Não concordo totalmente & 0 & $0 \%$ \\
\cline { 2 - 4 } Não concordo parcialmente & 1 & $2.2 \%$ \\
\cline { 2 - 4 } Indiferente & 3 & $6.5 \%$ \\
\hline Concordo parcialmente & 24 & $52.2 \%$ \\
\hline Concordo totalmente & 18 & $39.1 \%$ \\
\hline
\end{tabular}

Quanto ao indicador Reflexão crítica dos participantes e construção partilhada conhecimento os alunos envolveram-se positivamente e individualmente nesta reflexão contribuindo para a construção de um conhecimento conjunto no grande grupo (concordo totalmente com $41,3 \%$ e concordo parcialmente com 52,2\%), (ver Gráfico 14).

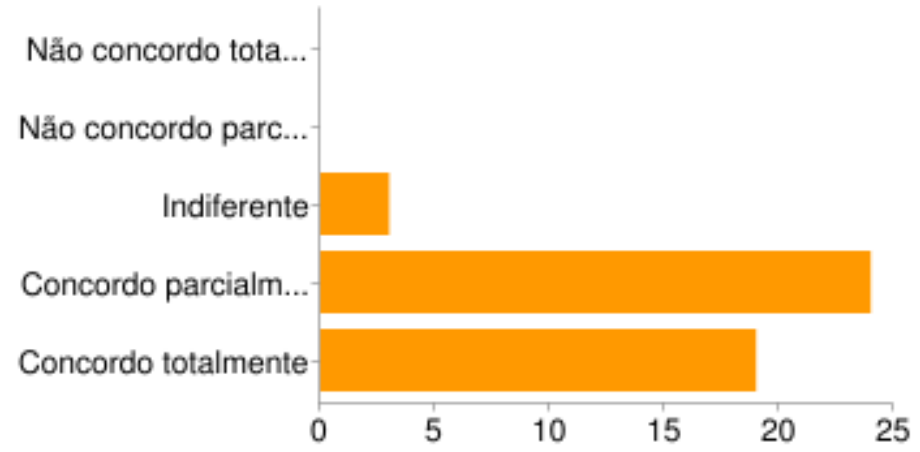

GRÁfico 14 - REFLEXÃo CRítiCA DOS PARTICIPANTES E CONSTRUÇÃo PARTILHADA CONHECIMENTO

\begin{tabular}{|l|l|l|}
\hline Não concordo totalmente & 0 & $0 \%$ \\
\hline Não concordo parcialmente & 0 & $0 \%$ \\
\hline Indiferente & 3 & $6.5 \%$ \\
\hline Concordo parcialmente & 24 & $52.2 \%$ \\
\hline Concordo totalmente & 19 & $41.3 \%$ \\
\hline
\end{tabular}




\section{Dimensão de Liderança e Moderação em Ambientes Online (Factores de Sustentabilidade)}

No indicador Identificação de Líderes e Moderadores esta percepção revelou dados diferenciados, pois apesar da maioria dos alunos terem consciência da presença de moderadores e líderes aquando da dinâmica de um artigo científico por parte de um grupo, não o sentiram na sua totalidade e atribuiram este papel a vários colegas. Desta forma os dados dividem-se na sua maioira em concordo totalmente, com $17,4 \%$; concordo parcialmente com 58,7 e indiferente com 17,4\%, tal como é visível no Gráfico 15.

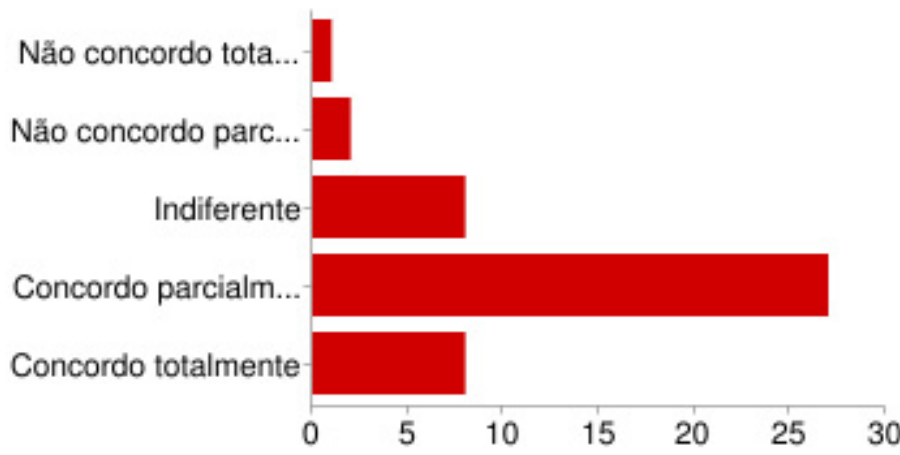

GrÁfico 15 - IdENTIFICAÇÃo de LídeRES E MOderadorES

\begin{tabular}{|l|l|l|}
\hline Não concordo totalmente & 1 & $2.2 \%$ \\
\hline Não concordo parcialmente & 2 & $4.3 \%$ \\
\hline Indiferente & 8 & $17.4 \%$ \\
\hline Concordo parcialmente & 27 & $58.7 \%$ \\
\hline Concordo totalmente & 8 & $17.4 \%$ \\
\hline
\end{tabular}

Relativamente ao indicador Estratégias de Liderança e Moderação encontramos também diversidade na forma como cada aluno perspetivou a liderança e moderação. Foi evidente que alguns alunos não conseguiram ter esta noção face aos restantes colegas por não considerar que o seu papel foi de moderador ou líder. Os dados revelam $17,4 \%$ numa concordância total; $65,2 \%$ numa concordância parcial; indiferente com $10,9 \%$ e ainda uma minoria que não concorda parcialmente $(2,2 \%)$ e não concorda totalmente $(4,3 \%)$ que este 
indicador teve evidência (ver Gráfico 16).

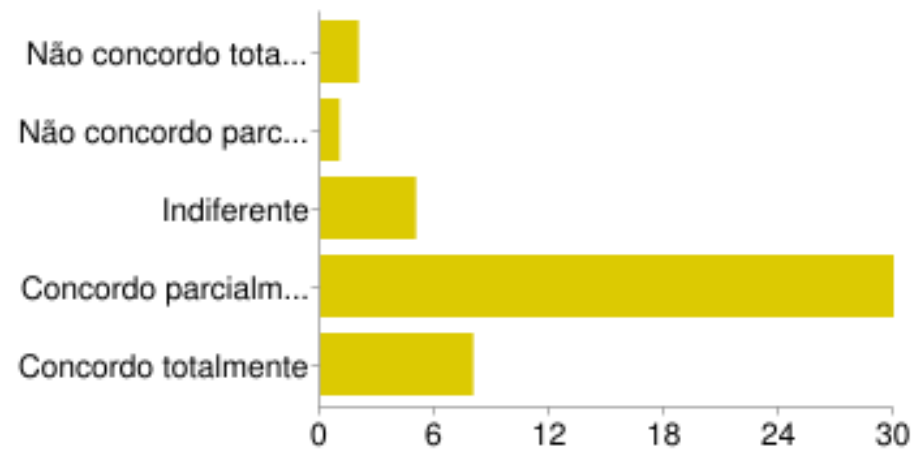

Gráfico 16 - Estratégias de LiderançA E ModeraçÃo

\begin{tabular}{|l|l|l|}
\hline Não concordo totalmente & 2 & $4.3 \%$ \\
\hline Não concordo parcialmente & 1 & $2.2 \%$ \\
\hline Indiferente & 5 & $10.9 \%$ \\
\hline Concordo parcialmente & 30 & $65.2 \%$ \\
\hline Concordo totalmente & 8 & $17.4 \%$ \\
\hline
\end{tabular}

Em concordância com os dados anteriores o indicador Evidência discursiva de orientação explícita revela dados diferenciados $19,6 \%$ numa concordância total; $63 \%$ numa concordância parcial; indiferente com $13 \%$ e ainda uma minoria que não concorda parcialmente $(2,2 \%)$ e não concorda totalmente $(2,2 \%)$ que este indicador teve evidência (ver Gráfico 17$)$.

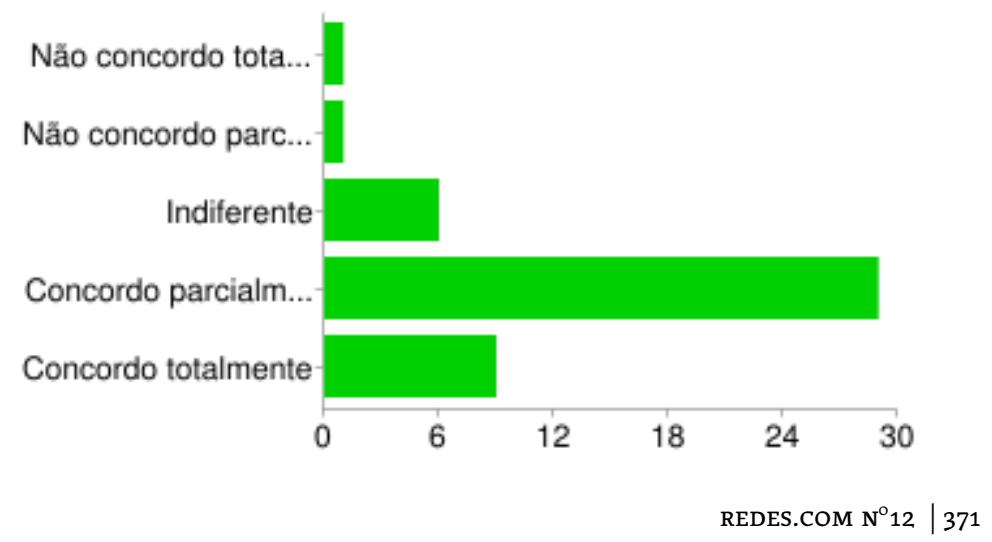


GRÁFICO 17 - EvidÊNCIA DISCURSIVA DE ORIENTAÇÃO EXPLÍCITA

\begin{tabular}{|l|l|l|}
\hline Não concordo totalmente & 1 & $2.2 \%$ \\
\hline Não concordo parcialmente & 1 & $2.2 \%$ \\
\hline Indiferente & 6 & $13 \%$ \\
\hline Concordo parcialmente & 29 & $63 \%$ \\
\hline Concordo totalmente & 9 & $19.6 \%$ \\
\hline
\end{tabular}

\section{Dimensão de Construção de Identidade em Ambientes Online (Diferenciação entre CoP)}

No indicador Percepção da presença cognitiva é evidente que os alunos sentiram de forma positiva a pertença a este espaço, que era de trabalho maioritariamente individual, mas também de grupo em alguns momentos, contribuindo para a construção de conhecimento (concordo totalmente com $28,3 \%$ e concordo parcialmente $67,4 \%$ ), (ver Gráfico 18 ).

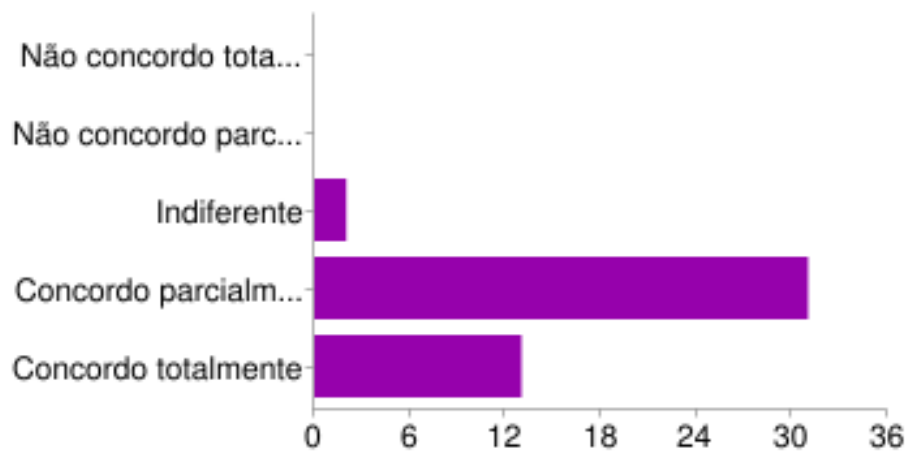

GRÁfico 18 - PERCEPÇÃo DA PRESENÇA COGNITIVA

\begin{tabular}{|l|l|l|}
\hline Não concordo totalmente & 0 & $0 \%$ \\
\hline Não concordo parcialmente & 0 & $0 \%$ \\
\hline Indiferente & 2 & $4.3 \%$ \\
\hline Concordo parcialmente & 31 & $67.4 \%$ \\
\hline Concordo totalmente & 13 & $28.3 \%$ \\
\hline
\end{tabular}


Relativamente ao indicador Percepção da presença social os alunos posicionamse de forma claramente positiva neste ambiente pessoal de aprendizagem, pois em determinados momentos em grupo este indicador foi concretizado (concordo totalmente com $37 \%$ e concordo parcialmente com $63 \%$ ), como se pode ver no Gráfico 19.

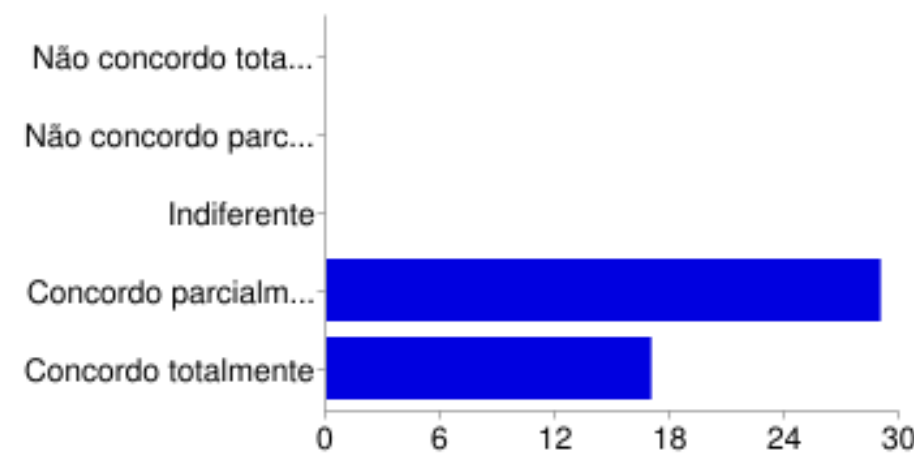

Gráfico 19 - PercepÇÃo dA PRESENÇA SOCIAL

\begin{tabular}{|l|l|l|}
\hline Não concordo totalmente & 0 & $0 \%$ \\
\hline Não concordo parcialmente & 0 & $0 \%$ \\
\hline Indiferente & 0 & $0 \%$ \\
\hline Concordo parcialmente & 29 & $63 \%$ \\
\hline Concordo totalmente & 17 & $37 \%$ \\
\hline
\end{tabular}

\section{CONSLUSÕES E CONSIDERAÇõES FINAIS}

A primeira recolha de dados foi concluída em Janeiro de 2015, no entanto, como estamos na segunda fase de recolha de dados apenas temos resultados parciais, referentes a uma turma dos alunos do curso de Educação Social da Escola Superior de Educação do Instituto Politécnico de Viseu - Portugal.

É possivel mostrar que esta experiência tem revelado ser do interesse dos alunos, pois a leitura de artigos científicos por vezes é algo que não acontece naturalmente, no decorrer das aulas presenciais. A constituição desta ambiente online de leitura e partilha de artigos de caráter científico, em torno das tecnologias na educação vem complementar as aulas presenciais, proporcionando o trabalho autónomo do aluno. 
$\mathrm{Na}$ apresentação dos resultados tivémos evidência de que todas as dimensões apresentam dados maioritariamente positivos. No entanto, a percentagem maior centrase numa concordância parcial em quase todos os indicadores. Neste processo de auto-avaliação é visível que apesar da participação de todos os alunos na leitura de artigos científicos, nem todos se empenharam da mesma forma quando a dinâmica previa a participação em grupo para reflexão das leituras individuais.

$\mathrm{Na}$ procura de encontrar dinâmicas e interações para a leitura de artigos científicos da especialidade, da Unidade Curricular das tecnologias na educação, os dados relativos à auto-avaliação revelam que existem claramente potencialidades dos ambientes híbridos e pessoais de aprendizagem, em contextos de Ensino Superior. Este experiência revela que se concretizou um espaço online que promoveu a leitura, a reflexão, o trabalho colaborativo e a oportunidade de gestão de conteúdos numa plataforma online.

Apesar dos resultados se posicionarem maioritariamente numa concordância parcial, seguida de uma concordância total, podemos afirmar que a experiência foi enriquecedora e bastante positiva nas diversas dimensões em análise. Foi possível fortalecer as relações interpessoais através da integração, partilha e comparação de informação, bem como a negociação, empenhamento mútuo e coorperação, permitindo uma interatividade cognitiva. Numa dimensão mais avançada os alunos consideram que também houve evidência de colaboração e construção de conhecimento, numa perspetiva individual e em posteriormente em grupo, dando lugar a uma dinâmica de interatividade metacognitiva. Todas interações, numa perspetiva individual, permitiram identificar colegas com estrátegias que os colocam num papel de líder ou moderador e, consequentemente, apropiaram-se deste espaço online definindo a sua identidade como espaço de leitura e reflexão, de artigos de caráter científico.

Esta experiência que iniciou este ano letivo 2014/2015 nas licenciaturas de Educação Social e Educação Básica, mas que tem acolhido alunos de outras licenciaturas da Escola Superior de Educação de Viseu está a ser bem aceite e tem proporcionado momentos diversificados online, pois a interações decorrem em espaços extra-aula presencial. Salientamos que numa antevisão dos resultados finais temos evidência de que os alunos consideram este espaço interessante ao nível da auto-aprendizagem, pois conseguem fazer a gestão do próprio tempo e sentem maior motivação para a leitura, reflexão e debate das mesmas. 


\section{REFERÊNCIAS}

AMADO, J., \& CARDOSO, A. P. (2014). A Investigação-Acção e as suas Modalidades. In I. d. U. d. Coimbra (Ed.), Manual de Investigação Qualitativa em Educação (2a ed., pp. 187-206). Coimbra.

ANDERSON, P. (2007, Feb. 2007). What is Web 2.0? Ideas, technologies and implications for education Retrieved 9 de Maio de 2008, from http://www. jisc.ac.uk/media/documents/techwatch/tsw0701b.pdf

BAIRD, D. E. (2006). Learning Styles 2.o: Digital, Social, and Always On Retrieved 10/06/2012, 2012, from http://www.debaird.net/blendededunet/2006/04/learning_styles.html

CABERO-ALMENARA, J., OSUNA, J. B., \& CEJUDO, M. C. L. (2010). El diseno de entornos personales de aprendizaje y la formacion de profesores en TIC. Digital Education Review(18).

DIAS, P. (2008). Da e-moderação à mediação colaborativa nas comunidades de aprendizagem. Educação, Formação \& Tecnologias, Vol. 1, pp.4-10.

DOWNES, S. (2005). E-learning 2.0 Retrieved Acedido em 11 de Abril de 2008, from http://www.elearnmag.org/subpage.cfm?section=articles\&article $=29-1$

HERNÁNDEZ, A. A. R. (2011, 21/10/2011). Educacion en la nube. “Cloud Education". La educacion a distancia del siglo XXI. Paper presented at the Hybrid Days.

HERNANDEZ, P. (2007). Tendencias de Web 2.0 aplicadas a la educación en línea. No Solo Usabilidad: Revista Multidisciplinar sobre Diseño de Interacción.

MIRANDA-PINTO, M. D. S. (2009). Processos de Colaboração e Liderança em Comunidades de Prática Online - O Caso da @rcaComum, uma Comunidade Ibero-Americana de Profissionais de Educação de Infância. $\mathrm{PhD}$, Universidade do Minho, Braga. Retrieved from http://repositorium.sdum.uminho.pt/ bitstream/1822/12571/4/Tese_Doutoramento_20-18-02-09.pdf

MIRANDA, M. S., VALENTE, L., MACHADO, M. J., VALLESCAR, D. D., MONTEIRO, A. F., \& OSÓRIO, A. J. (2008). Comunidades na Moodle: Projectos, Dinâmicas e Intencionalidades. Paper presented at the II Encontro Nacional Comunidades de Aprendizagem Moodle - CaldasMoodle'o8, Caldas da Rainha - Portugal.

O'REILLY, T. (2005a). Web 2.0: Compact Definition? Retrieved 9 de Junho de 2008, from http://radar.oreilly.com/2005/10/web-20-compact-definition. html

O'REILLY, T. (2005b). What Is Web 2.0 - Design Patterns and Business 
Models for the Next Generation of Software Retrieved 9 de Junho de 2008, from http://www.oreillynet.com/pub/a/oreilly/tim/ news/2005/09/30/what-is-web-20.html

PARDAL, L., \& CORREIA, E. (1995). Métodos e Técnicas de Investigação Social. Porto: Areal Editores.

ROMANI, C. C., \& KUKLINSKI, H. P. (2007). Planeta Web 2.o. Inteligencia colectiva o medios fast food Retrieved from www.planetawebdospuntocero. net doi:Versión 0.1 / Septiembre de 2007

SANTOS, C., PEDRO, L., \& ALMEIDA, S. (2011, Novembro 2011). Sapo Campus: promoção da utilização de serviços da Web social em contexto educativo. Educação, Formação \& Tecnologias, 4, 76-88.

SANTOS, C., PEDRO, L., \& ALMEIDA, S. (2012). Sapo campus: uma plataforma da web social para contextos educativos paper presented at the II Congresso Internacional TIC e Educação Lisboa. http://ticeduca.ie.ul.pt/ atas/atas.html 
POLÍTICAS PÚBLICAS Y DESARROLLO REGIONAL EN LA SOCIEDAD DE LA INFORMACIÓN:

TENDENCIAS Y RETOS 